\title{
Copy number profiling of oncogenes in ductal carcinoma in situ of the male breast
}

\author{
Marijn A Vermeulen', Shusma C Doebar², Carolien H M van Deurzen²,3, John W M Martens ${ }^{3,4}$, Paul J van Diest ${ }^{1}$ and \\ Cathy B Moelans ${ }^{1}$
}

1Department of Pathology, University Medical Center Utrecht, Utrecht University, Utrecht, The Netherlands 2Department of Pathology, Erasmus MC Cancer Institute, Erasmus University Medical Center, Rotterdam, The Netherlands ${ }^{3}$ BOOG Study Center/Dutch Breast Cancer Research Group, Amsterdam, The Netherlands ${ }^{4}$ Department of Medical Oncology and Cancer Genomics Netherlands, Erasmus MC Cancer Institute, Erasmus University Medical Center, Rotterdam, The Netherlands

Correspondence should be addressed to P J van Diest: p.j.vandiest@umcutrecht.nl

\begin{abstract}
Characterizing male breast cancer $(\mathrm{BC})$ and unraveling male breast carcinogenesis is challenging because of the rarity of this disease. We investigated copy number status of 22 BC-related genes in 18 cases of pure ductal carcinoma in situ (DCIS) and in 49 cases of invasive carcinoma (IC) with adjacent DCIS (DCIS-AIC) in males using multiplex ligation-dependent probe amplification (MLPA). Results were compared to female BC and correlated with survival. Overall, copy number ratio and aberration frequency including all 22 genes showed no significant difference between the 3 groups. Individual unpaired analysis revealed a significantly higher MTDH copy number ratio in IC compared to DCIS-AIC and pure DCIS ( $P=0.009$ and $P=0.038$, respectively). ADAM9 showed a significantly lower copy number aberration frequency in male $B C$, compared to female BC $(P=0.020)$. In DCIS-AIC, MTDH, CPD, CDC6 and TOP2A showed a lower frequency of copy number increase in males compared to females ( $P<0.001$ for all 4 genes). In IC, CPD gain and CCNE1 gain were independent predictors of poor overall survival. In conclusion, male DCIS and IC showed a similar copy number profile for 21 out of 22 interrogated $\mathrm{BC}$-related genes, illustrating their clonal relation and the genetically advanced state of male DCIS. MTDH showed a higher copy number ratio in IC compared to adjacent and pure DCIS and may therefore play a role in male breast carcinogenesis. Differences were detected between male and female DCIS for 4 genes pointing to differences in breast carcinogenesis between the sexes.
\end{abstract}

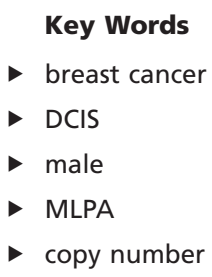

Endocrine-Related Cancer (2018) 25, 173-184

\section{Introduction}

Breast carcinogenesis is a multi-step process involving accumulation of DNA alterations and epigenetic changes. An important event during cancer development is oncogene amplification. Several genes have been described to be frequently amplified in female breast cancer (BC), of which the best-known example is the human epidermal growth factor receptor 2 (HER2). HER2 is amplified in $10-20 \%$ of female BC and is correlated to overall survival, time to relapse and response to trastuzumab, a humanized monoclonal anti-HER2 antibody (Slamon et al. 1987, Hudis 2007, Moelans et al. 2009). Other oncogenes that have been described to have clinical implications in 
female BC include the estrogen receptor (ESR1), epidermal growth factor receptor 1 (EGFR), MYC, topoisomerase IIa (TOP2A), fibroblast growth factor receptor 1 (FGFR1), cyclin E (CCNE1) and cyclin D1 (CCND1) (Holst et al. 2007, Rodriguez-Pinilla et al. 2007, Turner et al. 2010, Holm et al. 2012, Masuda et al. 2012, Almeida et al. 2014, Lundgren et al. 2015).

Invasive ductal type cancers (IDC) of the breast are thought to arise from ductal carcinoma in situ (DCIS) via parallel breast cancer progression pathways in which low-grade DCIS progresses to low-grade IDC and high-grade DCIS to high-grade IDC. These parallel pathways have been postulated to have distinct genomic aberrations (Hwang et al. 2004, Moelans et al. 2010a, Burger et al. 2013). Progression through grade is a phenomenon that has been rarely observed in BC (Schymik et al. 2012).

The final step in breast carcinogenesis, where the basement membrane of the ducts is breeched and the malignant epithelial cells infiltrate the surrounding stroma, is poorly understood. Several female BC studies have shown similar levels of gene amplification in DCIS and adjacent IC, indicating that these genes play an early role in breast carcinogenesis, but not in the progression from DCIS to invasive carcinoma (Aubele et al. 2000, Burkhardt et al. 2010, Moelans et al. 2010a). Furthermore, not all patients diagnosed with pure DCIS show progression to IC when left untreated. A previous study showed progression from low-grade DCIS to IC in 11/28 cases, the remaining cases showing an indolent course (Sanders et al. 2005). Therefore, unraveling the drivers that control the progression of DCIS to IC has proved to be challenging in female $\mathrm{BC}$, let alone in male $\mathrm{BC}$, where the rarity of the disease hampers thorough investigation. This knowledge is however needed to understand the biological course of male DCIS, to predict patients' outcome and to optimize DCIS treatment strategies. In this study, we compare pure DCIS, DCIS adjacent to IC (DCIS-AIC) and IC, as differences at molecular level have been described between these two types of DCIS in females, using RT-PCR (Doebar et al. 2017).

Male $\mathrm{BC}$ is a rare disease, accounting for approximately $1 \%$ of all BC (Siegel et al. 2015). Pure DCIS represents approximately 5\% (range 1-17\%) of all cancers in the male breast (Pappo et al. 2005). In female $\mathrm{BC}$, the diagnosis of pure DCIS is made in approximately $20 \%$ of all BC, and this difference in DCIS frequency between male and female $\mathrm{BC}$ can perhaps be explained by the participation of women in $\mathrm{BC}$ screening programs (Leonard \& Swain 2004).
There are many similarities but also important differences between male and female BC. There are differences in distribution of histologic subtypes as well as molecular subtypes; men tend to be older at the time of diagnosis and have more advanced disease at presentation compared to women (Giordano et al. 2004, Ge et al. 2009, Anderson et al. 2010, Kornegoor et al. 2012b). Also, there is some evidence suggesting differences in gene amplification frequencies (Kornegoor et al. 2012a). In a previous male BC study, gain of CCND1 and EGFR was more frequent in male $\mathrm{BC}$ compared to female $\mathrm{BC}$, and amplification of TRAF4 and EMSY was more often observed in female BC in comparison to male BC (Kornegoor et al. 2012a).

In the present study, we used multiplex ligationdependent probe amplification (MLPA) to investigate DNA copy number changes of 22 breast cancer-related genes in a group of male IC with adjacent DCIS and in a group of male pure DCIS. We correlated these copy number aberrations with clinicopathologic features and 10-year survival data and compared our results to a previous female BC study using a similar MLPA kit (Moelans et al. 2010a).

\section{Materials and methods}

\section{Patient material}

Patients with DCIS and adjacent IC or pure DCIS were enrolled from a previously selected large male BC cohort (Cardoso et al. 2015, Vermeulen et al. 2017). A subgroup of this initial population was selected based on availability of a tumor tissue block for central pathology review and sufficient tissue for DNA isolation. This resulted in a total of 51 cases with IC and adjacent DCIS and 20 cases of pure DCIS. Patient and tumor characteristics including age at diagnosis and 10-year overall survival status (defined as death due to any cause) were recorded. Data concerning BRCA1/2 testing was not available. Hematoxylin and eosin (H\&E) slides were reviewed by an experienced pathologist to confirm the diagnosis and to type and grade the IC according to the World Health Organization and modified Bloom and Richardson score (Elston \& Ellis 1991). DCIS was graded according to the classification by Holland and coworkers (1994). ER, PgR and HER2 were evaluated using immunohistochemistry and scored according to the Allred score (Allred et al. 1998) and ASCO-CAP guidelines (Wolff et al. 2013). The areas of interest (pure DCIS, DCIS-AIC and IC) were dissected either manually with a sterile scalpel when big enough or by laser capture microdissection using a Zeiss PALM 
MD3 laser microdissection system, from 5 sections $(4 \mu \mathrm{m})$ of formalin-fixed paraffin-embedded (FFPE) tissue blocks. Laser capture microdissection was done in cases with only small areas of DCIS or with abundant inflammatory cells surrounding the area of interest. The DNA was extracted by overnight incubation in proteinase $\mathrm{K}$ (10 mg/mL; Roche) at $56^{\circ} \mathrm{C}$, followed by boiling for $10 \mathrm{~min}$ and centrifugation. Normal male breast tissue was taken along as control. Results from a previous female BC study comparing DCIS and adjacent IC $(N=39)$ using a similar MLPA kit were used to compare copy number status in female and male BC (Moelans et al. 2010a).

Clinicopathological data are shown in Table 1. Hormone receptor status showed a high concordance (100\%) between DCIS and adjacent IC.

\section{Multiplex ligation-dependent probe amplification (MLPA)}

MLPA analysis was performed on all isolated DNA using the P078-C1 kit (MRC Holland, Amsterdam, The Netherlands), containing 41 probes targeting 22 breast cancer-related genes (Supplementary Table 1, see section on supplementary data given at the end of this article). MLPA was performed according to the manufacturer's instructions (MRC Holland), using an ABI 9700 PCR machine (Applied Biosystems). All tests were done in duplicate, and each MLPA run included 7 negative reference samples (3 healthy blood samples, 3 normal male breast FFPE samples and 1 normal female breast FFPE sample). The PCR products were separated by capillary electrophoresis on a 3730 DNA analyzer (Applied Biosystems). Gene copy numbers were analyzed using GeneScan analysis (Applied Biosystems) and Coffalyser. net software (MRC-Holland). For genes targeted by more than one probe, the mean of all probe ratios was calculated. Four of the 12 reference probes showed above average copy number variations and were excluded from further analyses (NRAP located at 10q25.3, TGIF1 located at 18p11.31, CETN3 located at 05q14.3 and SNCA located at 04q22.1).

Cut-off values were set as described previously with a copy number ratio of $<0.7$ for gene loss, 1.3-2.0 for copy number gain and $>2.0$ for amplification (Moelans et al. 2010a, Kornegoor et al. 2012a). Values between 0.7 and 1.3 were considered copy number neutral.

\section{Statistics}

Statistical calculations were done using SPSS, version 21.0. The Kruskal-Wallis test was used to compare the overall copy number ratio including all 22 genes between the 3

Table 1 Clinicopathological data of all male breast cancer cases (invasive carcinoma (IC), male pure ductal carcinoma in situ (pure DCIS) and DCIS adjacent to invasive carcinoma).

\begin{tabular}{|c|c|c|c|}
\hline & Invasive carcinoma & Adjacent DCIS & Pure DCIS \\
\hline \multicolumn{4}{|l|}{ Age (years) } \\
\hline Mean (range) & $63.2(37-85)$ & $63.2(37-85)$ & $62.3(37-76)$ \\
\hline \multicolumn{4}{|l|}{ Histologic subtype IC } \\
\hline Ductal type carcinoma & $46(90.2 \%)$ & & \\
\hline Mucinous carcinoma & $1(2 \%)$ & & \\
\hline Micropapillary carcinoma & $1(2 \%)$ & & \\
\hline Encapsulated papillary carcinoma & $1(2 \%)$ & & \\
\hline \multicolumn{4}{|l|}{ Mixed type } \\
\hline Ductal/micropapillary & $1(2 \%)$ & & \\
\hline Ductal/mucinous & $1(2 \%)$ & & \\
\hline \multicolumn{4}{|l|}{ Grade } \\
\hline 1 & $14(27.5 \%)$ & $11(21.6 \%)$ & $3(15 \%)$ \\
\hline 2 & $22(43.1 \%)$ & $32(62.7 \%)$ & $16(80 \%)$ \\
\hline 3 & $15(29.4 \%)$ & $8(15.7 \%)$ & $1(5 \%)$ \\
\hline \multicolumn{4}{|l|}{ ER } \\
\hline Positive & $51(100 \%)$ & $51(100 \%)$ & $20(100 \%)$ \\
\hline Negative & $0(0 \%)$ & $0(0 \%)$ & $0(0 \%)$ \\
\hline \multicolumn{4}{|l|}{ PR } \\
\hline Positive & $49(96.1 \%)$ & $49(96.1 \%)$ & $20(100 \%)$ \\
\hline Negative & $2(3.9 \%)$ & $2(3.9 \%)$ & $0(0 \%)$ \\
\hline \multicolumn{4}{|l|}{ HER2 } \\
\hline Positive & $2(3.9 \%)$ & $2(3.9 \%)$ & $1(5.3 \%)$ \\
\hline Negative & $49(96.1 \%)$ & $49(96.1 \%)$ & $18(94.7 \%)$ \\
\hline Missing & 0 & 0 & 1 \\
\hline
\end{tabular}




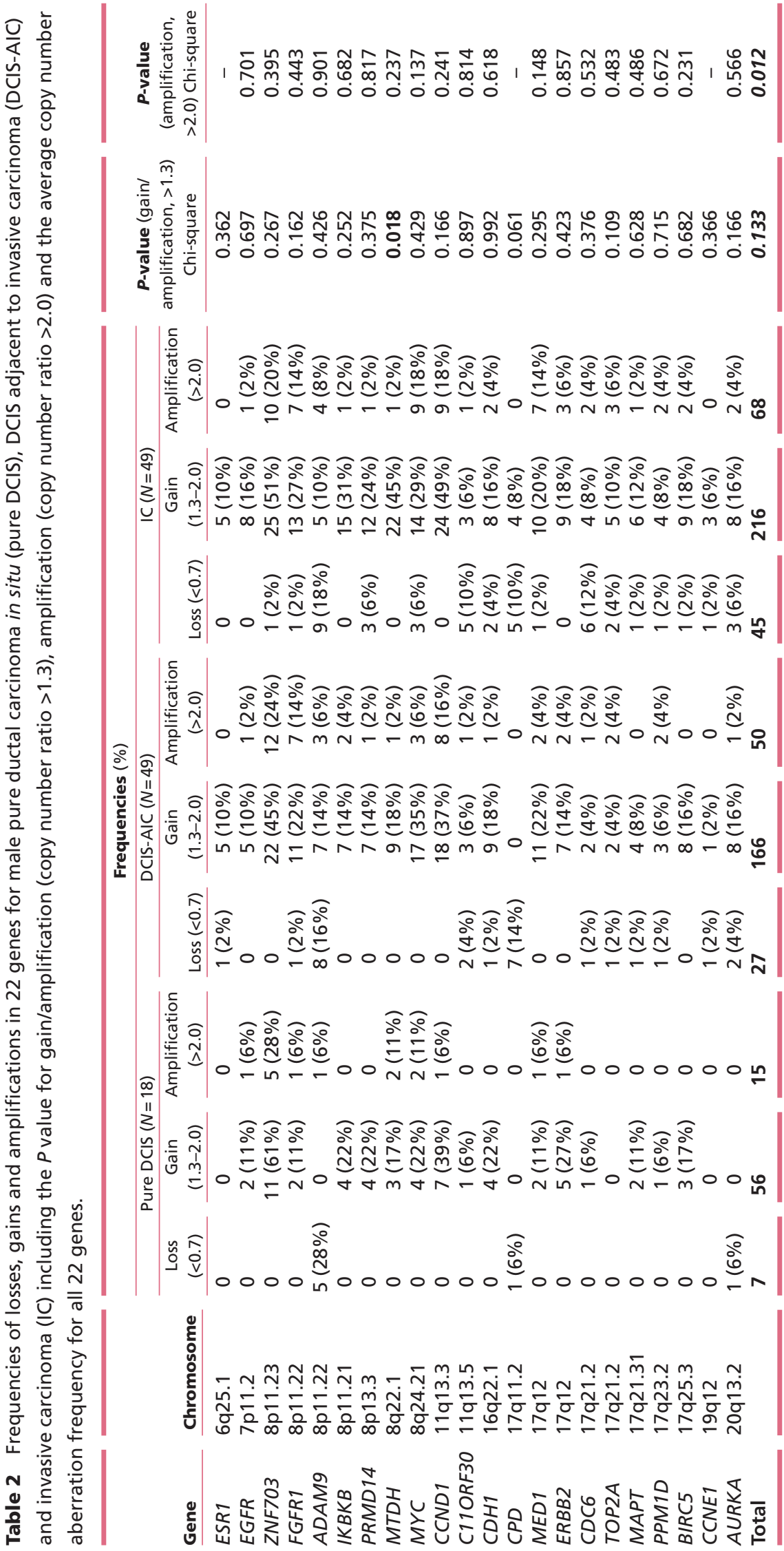


groups and to compare copy number ratios between the 3 groups for the 22 individual genes. After dichotomization, the chi-square test was used to compare the frequency of gains, amplifications or losses between groups. Mean copy number aberration frequency, for gains, amplifications and losses, including all genes was analyzed using the KruskalWallis test. Individual genes in pure DCIS and DCIS-AIC were compared using Mann-Whitney test for copy number ratio and chi-square for dichotomized results.

For paired data (IC and DCIS-AIC) the Wilcoxon signed-rank test was used to compare mean copy number ratio, and McNemar's test was used to compare copy number aberration frequency for the 22 individual genes.

The overall copy number ratios between low/ intermediate-grade and high-grade DCIS, as well as between low/intermediate-grade and high-grade IC were compared by Mann-Whitney test. Dichotomized data per grade category were evaluated by chi-square. $P$ values less than 0.05 were considered significant and correction for multiple comparisons was done using the Holm-Bonferroni method. Survival data were available for all IC and DCISAIC cases with a median follow-up of 8.1 years (range $0.86-19.56$ years). For univariate survival analysis, KaplanMeier curves were plotted and analyzed with the log-rank test. Multivariate survival analysis was done with Cox regression (backward LR) and included age, mitosis and grade.

Finally, unsupervised hierarchical clustering (Euclidian distance method) of copy number ratios was performed using the statistical program R (www.r-project.org).

\section{Results}

\section{Copy number ratio and aberration frequencies in DCIS and invasive carcinoma}

One case of invasive carcinoma, one case of DCIS-AIC and two cases of pure DCIS had an insufficient DNA yield and were excluded from further analysis, leaving 49 cases of DCIS with adjacent IC and 18 cases of pure DCIS suitable for copy number analysis. Supplementary Table 2 shows raw MLPA copy number data.

Table 2 summarizes copy number status for all 22 analyzed genes in each subgroup and Fig. 1 illustrates the copy number aberration frequency for each studied gene. The frequencies of losses, gains and amplifications were similar between the three groups $(P=0.167, P=0.132$ and $P=0.361$, respectively). Copy number gain/amplification (cut-off $>1.3$ ) was most frequently observed for ZNF703, CCND1 and MYC, but none of these genes showed a significant difference between the groups.

Overall, the copy number ratio including all 22 genes showed no significant difference between pure DCIS, DCIS-AIC and IC. At the individual gene level, MTDH showed a significantly higher copy number ratio in IC as compared to DCIS-AIC and pure DCIS $(P=0.009$ and $P=0.038$, respectively). Using a cut-off of $>1.3, M T D H$ showed a significantly higher aberration frequency in IC (46.9\%) as compared to DCIS-AIC $(20.4 \%)(P=0.005)$.

The copy number ratio for PRDM14, C11ORF30 and FGFR 1 was higher in DCIS-AIC compared to pure DCIS ( $P=0.007, P=0.027$ and $P=0.042$, respectively). However, these genes lost their significance after dichotomization.

No significant differences were found when comparing copy number aberration frequency (gain and amplification) with histologic subtype in IC, although these results should be interpreted with caution due to small sample sizes.

Paired comparison of DCIS-AIC and adjacent IC showed a high concordance of copy number status for all interrogated genes, with no significant differences present. The highest concordance rates were seen for the genes CCNE1 (95.9\%) and CDC6 (93.9\%). Copy number ratio was significantly higher in IC compared to the paired DCIS-AIC for MTDH $(P<0.001)$, MYC $(P=0.039)$,

Frequency of copy number increase (cut-off $>1.3$ )

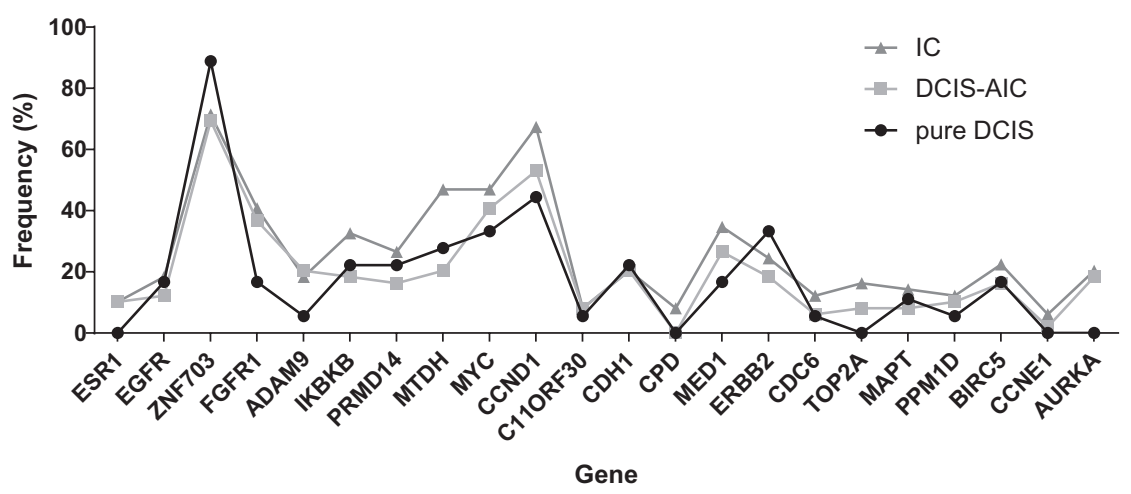

Figure 1

Frequencies of gain/amplification by MLPA for all 22 analyzed genes in male pure ductal carcinoma in situ (pure DCIS), DCIS adjacent to invasive carcinoma (DCIS-AIC) and invasive carcinoma (IC). 
Paired DCIS-AIC and IC: median copy number ratio

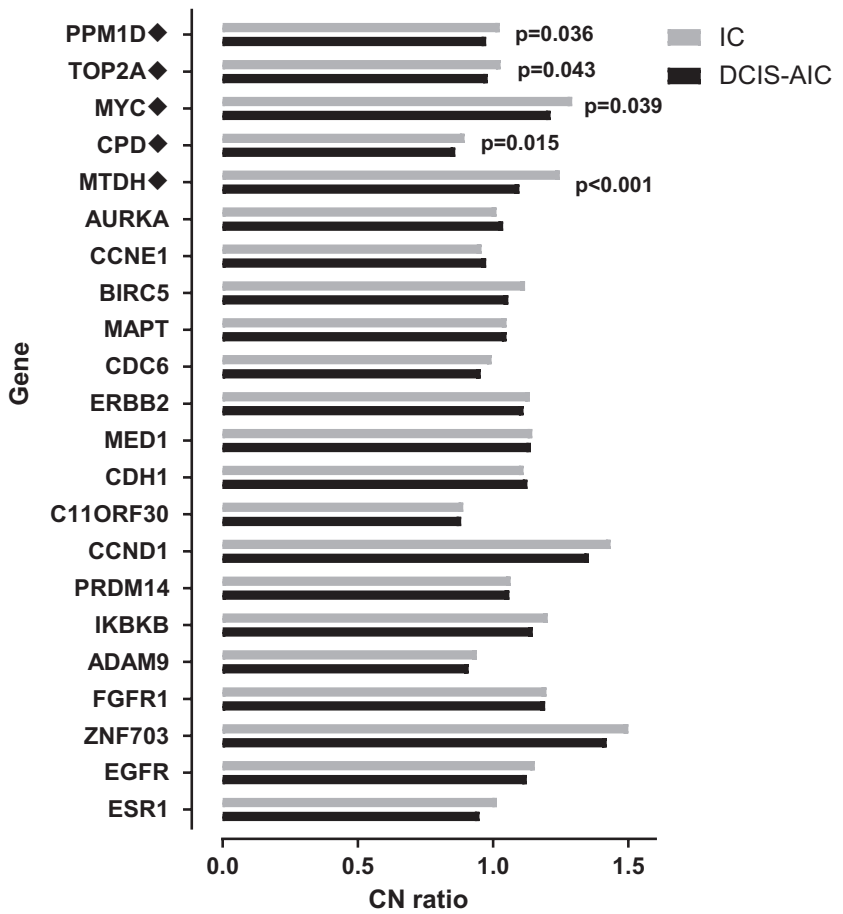

Figure 2

Median copy number ratio for all 22 analyzed genes in male invasive carcinoma (IC) and adjacent ductal carcinoma in situ (DCIS-AIC). Genes with a diamond show a significantly higher copy number ratio in IC.

CPD $(P=0.015)$, TOP2A $(P=0.043)$ and PPM1D $(P=0.036)$. Figure 2 shows the median copy number ratio for the 22 analyzed genes and Fig. 3 the copy number ratio for $M T D H, M Y C, C P D, T O P 2 A$ and PPM1D in paired IC and DCIS-AIC.

\section{Correlation between copy number and grade in DCIS-AIC and invasive carcinoma}

Copy number ratios and aberration frequencies were compared for DCIS-AIC and IC between low/ intermediate-grade and high-grade lesions. The mean copy number ratio was $1.17 \pm 0.22$ vs $1.32 \pm 0.25$ for low/ intermediate-grade vs high-grade DCIS-AIC $(P=0.165)$, and $1.15 \pm 0.16$ vs $1.42 \pm 0.44$ for low/intermediate grade vs high grade IC $(P=0.040)$. The average number of gains/ amplifications in the 22 analyzed genes was 3.7 vs 8.4 for low/intermediate-grade vs high-grade DCIS-AIC $(P=0.019)$ and 4.8 vs 8.3 for low/intermediate-grade vs high-grade IC $(P=0.037)$.

DCIS-AIC showed a significantly higher copy number ratio in high-grade lesions for the genes ESR1
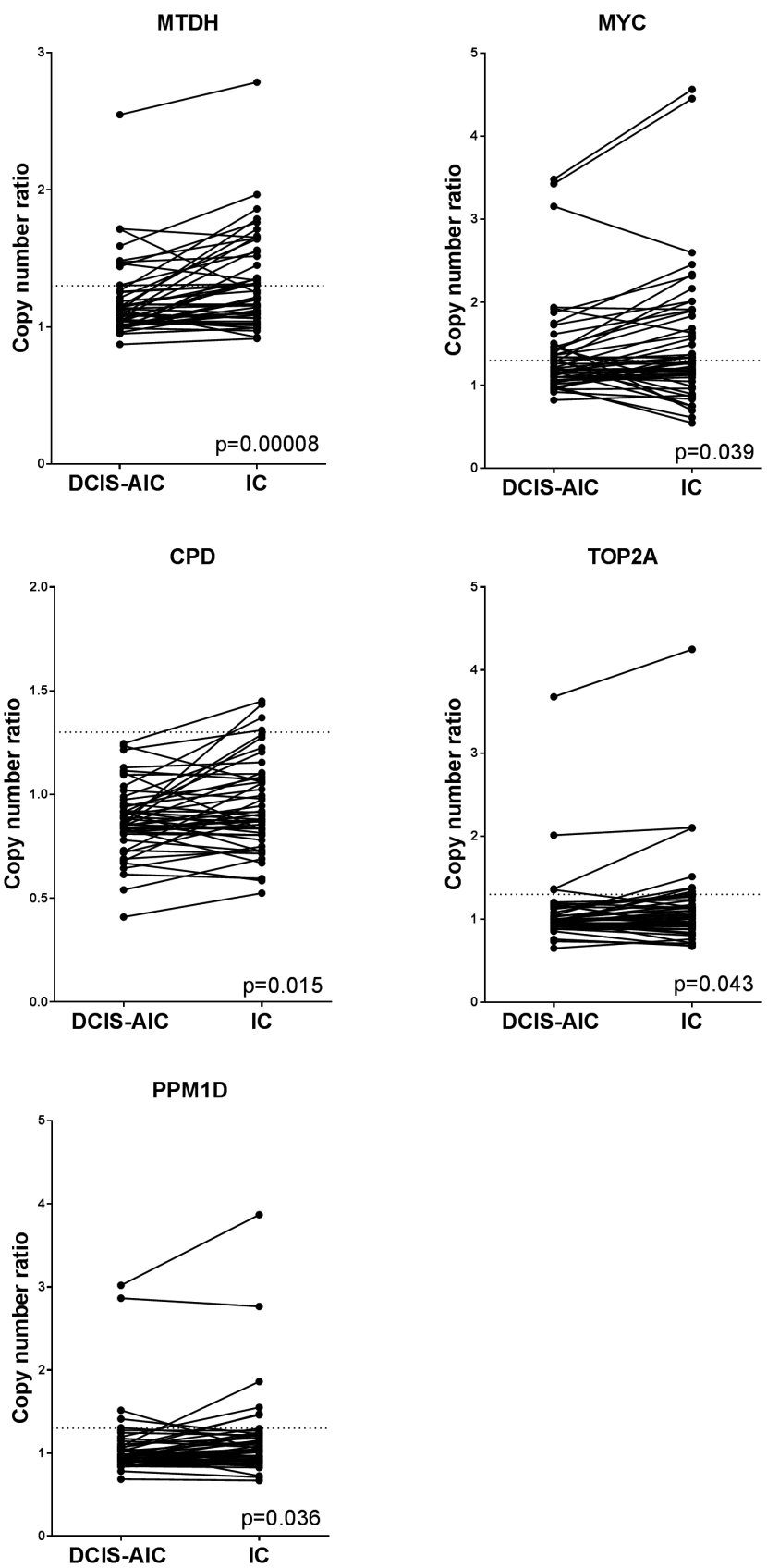

Figure 3

Copy number ratios for MTDH, MYC, CPD, TOP2A and PPM1D in male invasive carcinoma (IC) and adjacent ductal carcinoma in situ (DCIS-AIC).

$(P=0.047), P P M 1 D(P=0.004), B I R C 5 \quad(P=0.002)$ and CCNE1 $(P=0.005)$. After dichotomization (cut-off $>1.3)$, these differences remained significant $(P<0.001$, $P=0.002, \quad P=0.040$ and $P=0.014$, respectively). In addition, PRDM14 $(P=0.040)$, CDC6 $(P=0.003), T O P 2 A$ $(P=0.018)$ and AURKA $(P=0.006)$ showed a significantly higher copy number aberration frequency in high-grade DCIS-AIC lesions. Only MTDH showed a significantly 
higher frequency of amplification in high-grade DCIS-AIC $(P=0.007)$.

IC showed a significantly higher copy number ratio in high-grade lesions for the genes $\operatorname{EGFR}(P=0.005)$ and CCND1 $(P=0.005)$. Dichotomized data (cut-off $>1.3$ ) showed a significantly higher aberration frequency for ESR1 $(P=0.007)$, EGFR $(P=0.047), C 110 R F 30(P=0.001)$, CDC6 $(P=0.022)$ and PPM1D $(P=0.020)$ in high-grade lesions. ADAM9 $(P=0.029), \quad M Y C \quad(P=0.031), C C N D 1$ $(P=0.005), C D H 1 \quad(P=0.029)$, CDC6 $(P=0.013)$, TOP2A $(P=0.004)$ and PPM1D $(P=0.012)$ showed significant amplification more often in high-grade lesions.

After correction for multiple comparisons, only BIRC5 in DCIS-AIC remained significant with regard to copy number ratio difference (1.068 in low/intermediate grade vs 1.353 in high grade). For the dichotomized data, C11ORF30 in IC (17.1\% in low/intermediate grade vs $35.7 \%$ in high grade) and ESR1 in DCIS-AIC (2.4\% vs $57.1 \%)$ remained significant.

\section{Comparison of DCIS-AIC and IC copy number status between male and female breast cancer}

Results from a previous female BC study including 39 patients (IC and adjacent DCIS) were used to compare copy number status between female and male BC (Moelans et al. 2010a). This previous study used a prior version of the MLPA kit used here. Twenty genes were similar in both MLPA kits, with some differences in the probes used for the genes and were used for analysis.

In IC, ADAM9 showed a significantly lower copy number aberration frequency (cut-off $>1.3$ ) in male $\mathrm{BC}$ (22.5\%) compared to female BC (56.4\%) $(P=0.020)$. In DCIS, MTDH, CPD, CDC6 and TOP2A showed a lower frequency of copy number increase in male compared to female BC $(P<0.001$ for all 4 genes) (Fig. 4). The frequencies of amplifications (cut-off $>2.0$ ) and losses were similar between female and male BC.

In addition, we compared copy number aberration frequencies of 21/22 interrogated genes (EMSY data not available) with a large public female breast cancer cohort (METABRIC, www.cbioportal.org, (Curtis et al. 2012, Pereira et al. 2016)). Supplementary Table 3 shows a high amplification frequency similarity for all genes except for PRDM14 and MTDH, which both showed a difference of at least $10 \%$ in amplification frequency, with a higher amplification percentage in the METABRIC population $(N=2173)$.

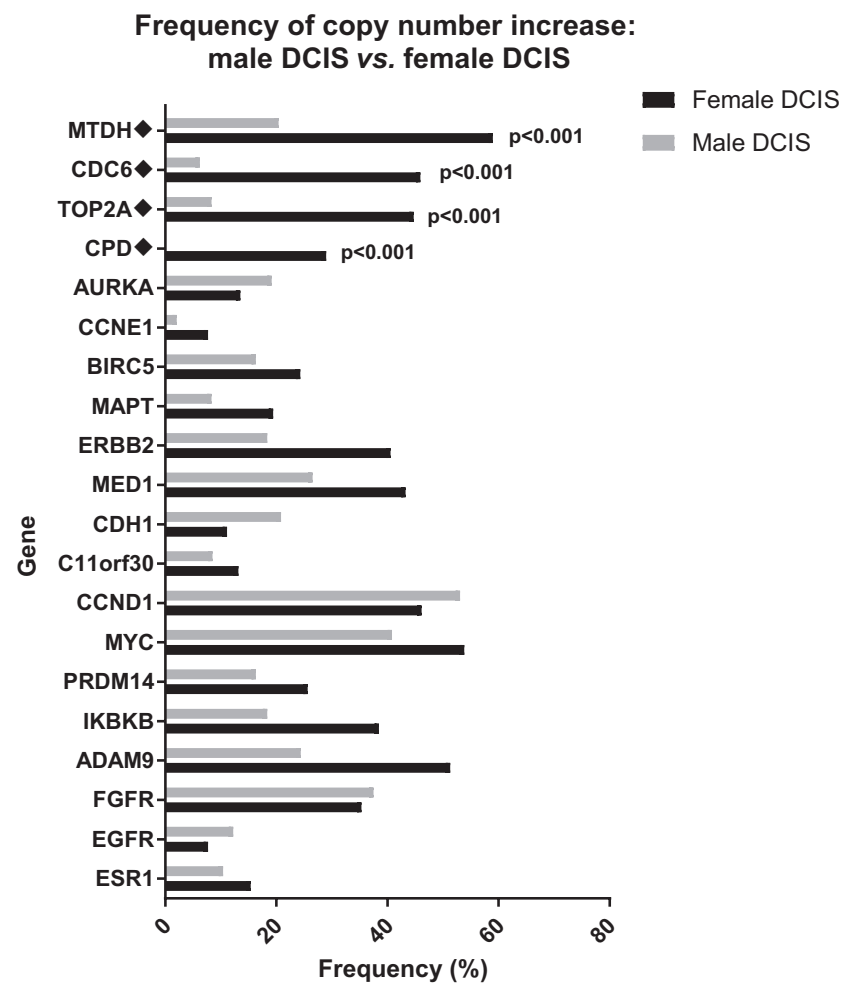

Figure 4

Frequency of copy number increase (cut-off $>1.3$ ) in female and male ductal carcinoma in situ (DCIS). Genes with a diamond show a significantly higher frequency of copy number gain in female BC.

\section{Correlation between copy number alterations and survival}

CPD and CCNE1 gain (no amplifications were observed) in IC were predictors of poor 10-year overall survival $(P=0.050$ and $P=0.001)$ and remained independent prognosticators when grade, mitoses and age were included in multivariable analysis ( $P=0.017$ (HR 5.1) and $P=0.003$ (HR 6.9)). Kaplan-Meier curves are presented in Fig. 5. None of the other interrogated genes were associated with survival.

\section{Cluster analysis of all male pure DCIS, DCIS-AIC and IC lesions}

Unsupervised hierarchical cluster analysis of all pure DCIS, DCIS-AIC and IC showed 2 main clusters that differed significantly according to grade (grade $1 / 2$ vs grade 3) with more high-grade lesions in cluster B $(n=29)$ compared to cluster A $(n=20) \quad(P=0.001)$ (Fig. 6). In addition, all genes showed a higher copy number ratio in cluster B. Of the 49 paired DCIS-AIC 


\section{CCNE1 10 year survival}

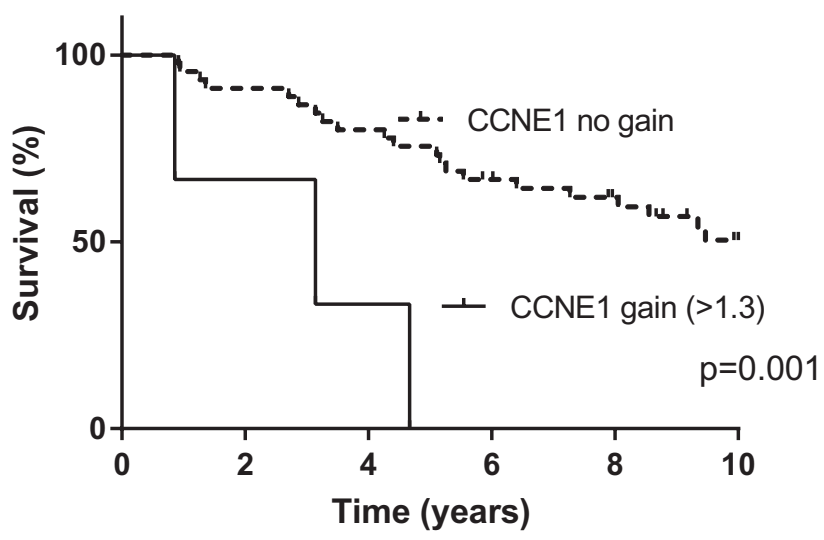

CPD 10 year survival

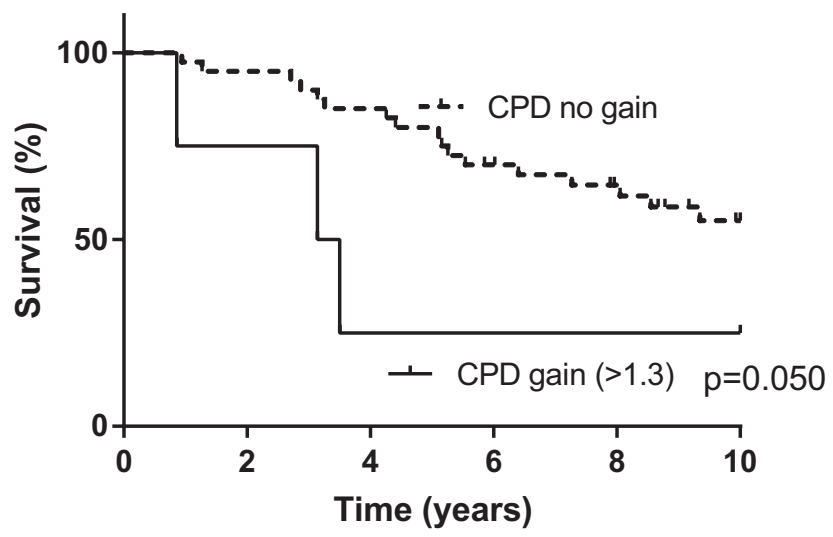

Figure 5

K Kaplan-Meier 10-year overall survival plots for CCNE1 gain and CPD gain.

and IC samples in the cluster analysis, 40 samples $(81.6 \%)$ were in the same cluster, and of these, 17 pairs (34.7\%) clustered closely together indicating that these adjacent in situ and invasive components share many genetic alterations.

\section{Discussion}

To discover drivers that may control the progression of DCIS to IC and to establish the precursor role of DCIS in male breast carcinogenesis, we studied copy number status of 22 breast cancer-related genes in IC, DCIS-AIC and pure DCIS of the male breast by MLPA. Overall, in line with previous studies on their female counterparts, there were only few copy number differences between male DCIS and IC (Aubele et al. 2000, Burkhardt et al. 2010, Moelans et al. 2010a).
Copy number ratios were similar in pure DCIS, DCISAIC and IC for most of the studied genes, indicating that copy number gain of the majority of these genes does not seem to play a significant role in the transition from male DCIS to IC. This finding is in line with a previous copy number and gene expression study in female BC (Moelans et al. 2010a). There was however one gene, $M T D H$, that showed a significantly higher copy number ratio and frequency of gain in IC as compared to DCISAIC. This implies that gain of $M T D H$ could play a role in the progression of DCIS to IC. In a previous MLPA-based male BC study, MTDH showed gain/amplification in $46 \%$ of the IC samples, similar to our results (Kornegoor et al. 2012a). MTDH is located on chromosome 8 and encodes Metadherin, a transmembrane protein that plays a key role in the activation of several signaling pathways including PI3K/Akt, NFk $\beta$, Wnt/ $\beta$ catenin and the MAPK pathways (Shi \& Wang 2015). These pathways play a role in cell proliferation, apoptosis, invasion, angiogenesis and metastasis. Metadherin is frequently overexpressed in female $\mathrm{BC}$ and overexpression correlates with advanced clinical stage, distant metastasis and an aggressive phenotype (Tokunaga et al. 2014). Moelans and coworkers compared MTDH copy number in 39 paired cases of female DCIS-AIC and IC but found no significant differences in copy number ratio, suggesting that this event may be specific for male breast carcinogenesis (Moelans et al. 2010a).

Interestingly, almost all of the analyzed genes showed copy number changes in DCIS, indicating that copy number gain is a relatively early event in male breast carcinogenesis. Paired analysis of IC and DCIS-AIC samples showed a high concordance of gain/amplification status between individual patients, supported by cluster analysis. This confirms the clonal relation between male DCIS and IC, as has also been accepted in female breast carcinogenesis (Moelans et al. 2010a). CCND1, a cell cycle regulatory protein, showed a high copy number aberration frequency in all three groups with 49\% CCND1 gain and 18\% CCND1 amplification in IC. CCND1 amplification is more frequent in ER-positive and PR tumors, so these high frequencies can be explained by the high rate of ER positivity (all cases being ER positive) and PR positivity (96\% of DCIS-AIC/IC cases and 100\% of pure DCIS cases being positive) in our male BC cohort (Reis-Filho et al. 2006).

Several genes showed a higher aberration frequency in high-grade lesions compared to low-grade lesions (ESR1, PPM1D, BIRC5, CCNE1, PRDM14, CDC6, TOP2A and AURKA for DCIS-AIC and ESR1, EGFR, C11ORF30, 


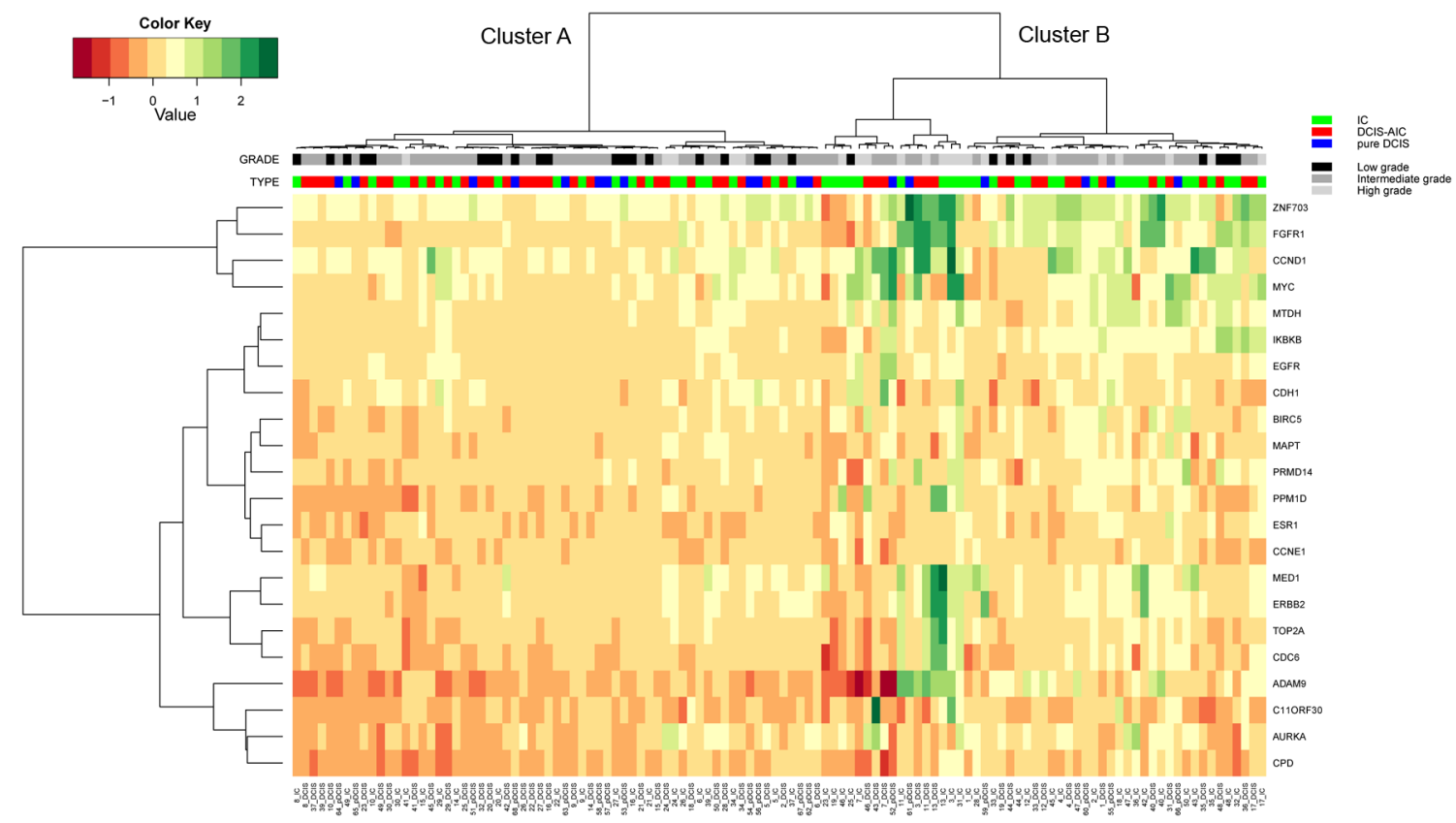

\section{Figure 6}

Unsupervised hierarchical cluster analysis of 22 genes in male breast cancer lesions, including pure ductal carcinoma in situ (DCIS), DCIS adjacent to invasive carcinoma (DCIS-AIC) and invasive carcinoma (IC).

CDC6 and PPM1D for IC). Also, the average copy number ratio was higher in high grade IC compared to low/ intermediate-grade IC. After correction for multiple comparisons, BIRC5 copy number ratio and ESR1 gain in DCIS-AIC and C11ORF30 gain in IC were significantly higher/more frequent in high-grade lesions. Although the sample sizes of high-grade DCIS-AIC and highgrade IC were small ( $n=7$ and $n=14$, respectively), this does suggest that tumors with a higher copy number gain have a tendency to have higher histological grade, as previously demonstrated in male BC (Kornegoor et al. 2012a). BIRC5 codes for the protein Survivin, a regulatory protein involved in cell proliferation and apoptosis. It has been extensively studied in female BC where an increased expression of Survivin was correlated with a higher risk of recurrence and with a decreased overall survival rate (Davis et al. 2007, Li et al. 2014). ESR1 codes for estrogen receptor alpha, a transcription factor located on chromosome 6q25 and an important therapeutic target in female $\mathrm{BC}$ with tamoxifen being the standard endocrine therapy for ER-positive breast cancers (Holst et al. 2007). In a previous study using MLPA, ESR1 amplification and gain were shown in $2 \%$ and $6 \%$ of 135 female breast tumors, respectively (Moelans et al. 2011). C11ORF30 (also known as EMSY) is a transcription regulatory protein that can compromise BRCA2 function in sporadic breast cancer and ovarian cancer
(Hughes-Davies et al. 2003). In female BC, it has been associated with a reduced overall survival in ER-positive patients (Kirkegaard et al. 2008).

Upon comparison of our findings with female BC, a high concordance was evident, especially for IC. For DCIS, 4 genes (MTDH, CPD, CDC6 and TOP2A) showed a higher frequency of gain in female $\mathrm{BC}$, although no differences in amplification frequency were observed. Copy number aberration frequencies for 21 genes were also compared with a large female breast cancer cohort (METABRIC, www.cbioportal.org, (Curtis et al. 2012, Pereira et al. 2016)), showing a high amplification frequency similarity.

Two of the 22 studied genes showed a correlation with overall survival. CCNE1 and CPD gain were both indicative of a decreased 10-year overall survival; however, the number of cases showing gain of these genes ( $n=3$ and $n=4$, respectively) were small and none of the cases showed amplification. Also, treatment regimens and lymph node status were not known so could not be included in the survival analysis. Therefore, results should be interpreted with caution. High levels of Cyclin E have been described to have prognostic value in female breast cancer, especially as a predictor of endocrine therapy failure (Keyomarsi et al. 2002, Span et al. 2003).

$C P D$ has been investigated in breast cancer cell lines (MCF-7 cells), where prolactin/17 $\beta$-estradiol-induced 
cell surface CPD increased intracellular NO production, which increased the survival and inhibited apoptosis (Abdelmagid \& Too 2008).

Although a limitation of this study is the relatively small study population, it should be noted that male BC is rare, male DCIS is even rarer, and our DCIS samples have been extracted from a large cohort study and were enriched for tumor cells by scalpel or laser microdissection. We used MLPA for copy number analysis, a multiplex PCR-based method that simultaneously assesses relative copy numbers of a variety of genes in a quantitative way. The major advantage of this technique is that it requires only minimal amounts of small DNA fragments, which makes it very suitable to study small lesions in paraffin-embedded tissue, such as DCIS (Moelans et al. 2009). The MLPA kit used was predesigned by the manufacturer and contains 22 cancerrelated genes that often show copy number aberrations in female BC (Moelans et al. 2010a,b). Although there are some genetic differences between male and female $\mathrm{BC}$, we expected the bigger part of these genes to play a role in male breast carcinogenesis as well (Moelans et al. 2010b). We did not include PIK3CA, TP53 and GATA3, possible important genomic drivers in female $\mathrm{BC}$ and described to be frequently mutated in female BC (2012). In this study, we only focused on copy number variations and not on specific mutations.

In conclusion, this MLPA-based study showed a similar copy number status for 21 out of 22 studied breast cancerrelated genes in male DCIS and IC, illustrating the clonal relation between male DCIS and adjacent IC, and the genetically advanced state of male DCIS. MTDH showed a higher copy number ratio and aberration frequency in IC compared to DCIS and could therefore play a role in the transition of male DCIS to IC.

\section{Supplementary data}

This is linked to the online version of the paper at https://doi.org/10.1530/ ERC-17-0338.

\section{Declaration of interest}

The authors declare that there is no conflict of interest that could be perceived as prejudicing the impartiality of the research reported.

\section{Funding}

The Dutch participation in the International Male Breast Cancer Program is supported by the Dutch Pink Ribbon.

\section{Acknowledgements}

As the patients were selected from the Dutch part of the International Male BC program, 10085, we are grateful to the European Organization for Research and Treatment of Cancer, the Translational Breast Cancer Research Consortium, Breast International Group, North American Breast Cancer Group, the Dutch Breast Cancer Research Group (BOOG), the Nationwide Network and Registry of Histo- and Cytopathology in the Netherlands (PALGA) and the Netherlands Cancer Registry.

\section{References}

Abdelmagid SA \& Too CK 2008 Prolactin and estrogen up-regulate carboxypeptidase-d to promote nitric oxide production and survival of mcf-7 breast cancer cells. Endocrinology 149 4821-4828. (https://doi.org/10.1210/en.2008-0145)

Allred DC, Harvey JM, Berardo M \& Clark GM 1998 Prognostic and predictive factors in breast cancer by immunohistochemical analysis. Modern Pathology 11 155-168.

Almeida D, Gerhard R, Leitao D, Davilla C, Damasceno M \& Schmitt F 2014 Topoisomerase II-alfa gene as a predictive marker of response to anthracyclines in breast cancer. Pathology: Research and Practice 210 675-679. (https://doi.org/10.1016/j.prp.2014.06.017)

Anderson WF, Jatoi I, Tse J \& Rosenberg PS 2010 Male breast cancer: a population-based comparison with female breast cancer. Journal of Clinical Oncology 28 232-239. (https://doi.org/10.1200/ JCO.2009.23.8162)

Aubele M, Mattis A, Zitzelsberger H, Walch A, Kremer M, Welzl G, Hofler H \& Werner M 2000 Extensive ductal carcinoma in situ with small foci of invasive ductal carcinoma: evidence of genetic resemblance by CGH. International Journal of Cancer $\mathbf{8 5} 82-86$. (https://doi.org/10.1002/(SICI)1097-0215(20000101)85:1<82::AIDIJC15>3.0.CO;2-S)

Baquero MT, Lostritto K, Gustavson MD, Bassi KA, Appia F, Camp RL, Molinaro AM, Harris LN \& Rimm DL 2011 Evaluation of prognostic and predictive value of microtubule associated protein tau in two independent cohorts. Breast Cancer Research 13 R85. (https://doi. org/10.1186/bcr2937)

Burger H, de Boer M, van Diest PJ \& Korsching E 2013 Chromosome $16 \mathrm{q}$ loss - a genetic key to the understanding of breast carcinogenesis. Histology and Histopathology 28 311-320.

Burkhardt L, Grob TJ, Hermann I, Burandt E, Choschzick M, Janicke F, Muller V, Bokemeyer C, Simon R, Sauter G, et al. 2010 Gene amplification in ductal carcinoma in situ of the breast. Breast Cancer Research and Treatment 123 757-765. (https://doi.org/10.1007/ s10549-009-0675-8)

Cancer Genome Atlas Network. Comprehensive molecular portraits of human breast tumours. Nature 490 61-70. (https://doi.org/10.1038/ nature11412)

Cardoso F, Bartlett J, Slaets L, Deurzen CV, Leeuwen-Stok EV, Porter P, Linderholm B, Hedenfalk I \& Giordano S 2015 Characterization of male breast cancer: first results of the EORTC10085/TBCRC/BIG/ NABCG International Male BC Program. Cancer Research 75 S6-05-S6-05. (https://doi.org/10.1158/1538-7445.SABCS14-S6-05)

Chin K, DeVries S, Fridlyand J, Spellman PT, Roydasgupta R, Kuo WL, Lapuk A, Neve RM, Qian Z, Ryder T, et al. 2006 Genomic and transcriptional aberrations linked to breast cancer pathophysiologies. Cancer Cell 10 529-541. (https://doi.org/10.1016/j.ccr.2006.10.009)

Cleton-Jansen AM 2002 E-cadherin and loss of heterozygosity at chromosome 16 in breast carcinogenesis: different genetic pathways in ductal and lobular breast cancer? Breast Cancer Research 4 5-8. (https://doi.org/10.1186/bcr416)

Cui J, Germer K, Wu T, Wang J, Luo J, Wang SC, Wang Q \& Zhang X 2012 Cross-talk between HER2 and MED1 regulates tamoxifen
(2) 2018 Society for Endocrinology Published by Bioscientifica Ltd. Printed in Great Britain 
resistance of human breast cancer cells. Cancer Research $\mathbf{7 2}$ 5625-5634. (https://doi.org/10.1158/0008-5472.CAN-12-1305)

Curtis C, Shah SP, Chin SF, Turashvili G, Rueda OM, Dunning MJ, Speed D, Lynch AG, Samarajiwa S, Yuan Y, et al. 2012 The genomic and transcriptomic architecture of 2,000 breast tumours reveals novel subgroups. Nature 486 346-352.

Davis LM, Harris C, Tang L, Doherty P, Hraber P, Sakai Y, Bocklage T, Doeden K, Hall B, Alsobrook J, et al. 2007 Amplification patterns of three genomic regions predict distant recurrence in breast carcinoma. Journal of Molecular Diagnostics 9 327-336. (https://doi. org/10.2353/jmoldx.2007.060079)

Doebar SC, Sieuwerts AM, de Weerd V, Stoop H, Martens JWM \& van Deurzen CHM 2017 Gene expression differences between ductal carcinoma in situ with and without progression to invasive breast cancer. American Journal of Pathology 187 1648-1655. (https://doi. org/10.1016/j.ajpath.2017.03.012)

Elston CW \& Ellis IO 1991 Pathological prognostic factors in breast cancer. I. The value of histological grade in breast cancer: experience from a large study with long-term follow-up. Histopathology 19 403-410. (https://doi.org/10.1111/j.1365-2559.1991.tb00229.x)

Ge Y, Sneige N, Eltorky MA, Wang Z, Lin E, Gong Y \& Guo M 2009 Immunohistochemical characterization of subtypes of male breast carcinoma. Breast Cancer Research 11 R28. (https://doi.org/10.1186/ bcr2258)

Giordano SH, Cohen DS, Buzdar AU, Perkins G \& Hortobagyi GN 2004 Breast carcinoma in men: a population-based study. Cancer 101 51-57. (https://doi.org/10.1002/cncr.20312)

Gonzalez S, Klatt P, Delgado S, Conde E, Lopez-Rios F, SanchezCespedes M, Mendez J, Antequera F \& Serrano M 2006 Oncogenic activity of Cdc6 through repression of the INK4/ARF locus. Nature 440 702-706. (https://doi.org/10.1038/nature04585)

Holland R, Peterse JL, Millis RR, Eusebi V, Faverly D, van de Vijver MJ \& Zafrani B 1994 Ductal carcinoma in situ: a proposal for a new classification. Seminars in Diagnostic Pathology 11 167-180.

Holm K, Staaf J, Jonsson G, Vallon-Christersson J, Gunnarsson H, Arason A, Magnusson L, Barkardottir RB, Hegardt C, Ringner M, et al. 2012 Characterisation of amplification patterns and target genes at chromosome 11q13 in CCND1-amplified sporadic and familial breast tumours. Breast Cancer Research and Treatment 133 583-594. (https://doi.org/10.1007/s10549-011-1817-3)

Holst F, Stahl PR, Ruiz C, Hellwinkel O, Jehan Z, Wendland M, Lebeau A, Terracciano L, Al-Kuraya K, Janicke F, et al. 2007 Estrogen receptor alpha (ESR1) gene amplification is frequent in breast cancer. Nature Genetics 39 655-660. (https://doi.org/10.1038/ng2006)

Hou J, Wang Z, Yang L, Guo X \& Yang G 2014 The function of EMSY in cancer development. Tumor Biology 35 5061-5066. (https://doi. org/10.1007/s13277-013-1584-3)

Hudis CA 2007 Trastuzumab - mechanism of action and use in clinical practice. New England Journal of Medicine 357 39-51. (https://doi. org/10.1056/NEJMra043186)

Hughes-Davies L, Huntsman D, Ruas M, Fuks F, Bye J, Chin SF, Milner J, Brown LA, Hsu F, Gilks B, et al. 2003 EMSY links the BRCA2 pathway to sporadic breast and ovarian cancer. Cell 115 523-535. (https://doi. org/10.1016/S0092-8674(03)00930-9)

Hwang ES, DeVries S, Chew KL, Moore DH 2nd, Kerlikowske K, Thor A, Ljung BM \& Waldman FM 2004 Patterns of chromosomal alterations in breast ductal carcinoma in situ. Clinical Cancer Research 10 5160-5167. (https://doi.org/10.1158/1078-0432.CCR-04-0165)

Keyomarsi K, Tucker SL, Buchholz TA, Callister M, Ding Y, Hortobagyi GN, Bedrosian I, Knickerbocker C, Toyofuku W, Lowe M, et al. 2002 Cyclin E and survival in patients with breast cancer. New England Journal of Medicine 347 1566-1575. (https://doi.org/10.1056/ NEJMoa021153)

Kirkegaard T, Nielsen KV, Jensen LB, Campbell FM, Muller S, Tovey SM, Brown S, Cooke TG \& Bartlett JM 2008 Genetic alterations of
CCND1 and EMSY in breast cancers. Histopathology 52 698-705. (https://doi.org/10.1111/j.1365-2559.2008.03007.x)

Kornegoor R, Moelans CB, Verschuur-Maes AH, Hogenes MC, de Bruin PC, Oudejans JJ, Marchionni L \& van Diest PJ 2012a Oncogene amplification in male breast cancer: analysis by multiplex ligation-dependent probe amplification. Breast Cancer Research and Treatment 135 49-58. (https://doi.org/10.1007/s10549-012-2051-3)

Kornegoor R, Verschuur-Maes AH, Buerger H, Hogenes MC, de Bruin PC, Oudejans JJ, van der Groep P, Hinrichs B \& van Diest PJ $2012 b$ Molecular subtyping of male breast cancer by immunohistochemistry. Modern Pathology 25 398-404. (https://doi. org/10.1038/modpathol.2011.174)

Lambros MB, Natrajan R, Geyer FC, Lopez-Garcia MA, Dedes KJ, Savage K, Lacroix-Triki M, Jones RL, Lord CJ, Linardopoulos S, et al. 2010 PPM1D gene amplification and overexpression in breast cancer: a qRT-PCR and chromogenic in situ hybridization study. Modern Pathology 23 1334-1345. (https://doi.org/10.1038/ modpathol.2010.121)

Leonard GD \& Swain SM 2004 Ductal carcinoma in situ, complexities and challenges. Journal of the National Cancer Institute 96 906-920. (https://doi.org/10.1093/jnci/djh164)

Li Y, Ma X, Wu X, Liu X \& Liu L 2014 Prognostic significance of survivin in breast cancer: meta-analysis. Breast Journal 20 514-524. (https://doi.org/10.1111/tbj.12303)

Lundgren C, Ahlin C, Holmberg L, Amini RM, Fjallskog ML \& Blomqvist C 2015 Cyclin E1 is a strong prognostic marker for death from lymph node negative breast cancer. A population-based casecontrol study. Acta Oncologica 54 538-544.

Masuda H, Zhang D, Bartholomeusz C, Doihara H, Hortobagyi GN \& Ueno NT 2012 Role of epidermal growth factor receptor in breast cancer. Breast Cancer Research and Treatment 136 331-345. (https://doi.org/10.1007/s10549-012-2289-9)

Mazzocca A, Coppari R, De Franco R, Cho JY, Libermann TA, Pinzani M \& Toker A 2005 A secreted form of ADAM9 promotes carcinoma invasion through tumor-stromal interactions. Cancer Research $\mathbf{6 5}$ 4728-4738. (https://doi.org/10.1158/0008-5472.CAN-04-4449)

Moelans CB, de Weger RA, van Blokland MT, Ezendam C, Elshof S, Tilanus MG \& van Diest PJ 2009 HER-2/neu amplification testing in breast cancer by multiplex ligation-dependent probe amplification in comparison with immunohistochemistry and in situ hybridization. Cellular Oncology 31 1-10.

Moelans CB, de Weger RA, Monsuur HN, Maes AH \& van Diest PJ 2010a Molecular differences between ductal carcinoma in situ and adjacent invasive breast carcinoma: a multiplex ligation-dependent probe amplification study. Analytical Cellular Pathology 33 165-173. (https://doi.org/10.1155/2010/829358)

Moelans CB, de Weger RA, Monsuur HN, Vijzelaar R \& van Diest PJ $2010 b$ Molecular profiling of invasive breast cancer by multiplex ligation-dependent probe amplification-based copy number analysis of tumor suppressor and oncogenes. Modern Pathology 23 1029-1039. (https://doi.org/10.1038/modpathol.2010.84)

Moelans CB, Monsuur HN, de Pinth JH, Radersma RD, de Weger RA \& van Diest PJ 2011 ESR1 amplification is rare in breast cancer and is associated with high grade and high proliferation: a multiplex ligation-dependent probe amplification study. Cellular Oncology 34 489-494. (https://doi.org/10.1007/s13402-011-0045-5)

Nagalingam A, Tighiouart M, Ryden L, Joseph L, Landberg G, Saxena NK \& Sharma D 2012 Med1 plays a critical role in the development of tamoxifen resistance. Carcinogenesis 33 918-930. (https://doi. org/10.1093/carcin/bgs105)

Nishikawa N, Toyota M, Suzuki H, Honma T, Fujikane T, Ohmura T, Nishidate T, Ohe-Toyota M, Maruyama R, Sonoda T, et al. 2007 Gene amplification and overexpression of PRDM14 in breast cancers. Cancer Research 67 9649-9657. (https://doi.org/10.1158/0008-5472. CAN-06-4111)
(2) 2018 Society for Endocrinology Published by Bioscientifica Ltd. Printed in Great Britain 
Ooi A, Inokuchi M, Harada S, Inazawa J, Tajiri R, Kitamura SS, Ikeda H, Kawashima H \& Dobashi Y 2012 Gene amplification of ESR1 in breast cancers - fact or fiction? A fluorescence in situ hybridization and multiplex ligation-dependent probe amplification study. Journal of Pathology 227 8-16. (https://doi.org/10.1002/path.3974)

Pappo I, Wasserman I \& Halevy A 2005 Ductal carcinoma in situ of the breast in men: a review. Clinical Breast Cancer 6 310-314. (https://doi.org/10.3816/CBC.2005.n.033)

Park K, Han S, Shin E, Kim HJ \& Kim JY 2007 EGFR gene and protein expression in breast cancers. European Journal of Surgical Oncology 33 956-960. (https://doi.org/10.1016/j.ejso.2007.01.033)

Pereira B, Chin SF, Rueda OM, Vollan HK, Provenzano E, Bardwell HA, Pugh M, Jones L, Russell R, Sammut SJ, et al. 2016 The somatic mutation profiles of 2,433 breast cancers refines their genomic and transcriptomic landscapes. Nature Communications 711479. (https://doi.org/10.1038/ncomms11479)

Petrakis TG, Vougas K \& Gorgoulis VG 2012 Cdc6: a multi-functional molecular switch with critical role in carcinogenesis. Transcription 3 124-129. (https://doi.org/10.4161/trns.20301)

Reis-Filho JS, Savage K, Lambros MB, James M, Steele D, Jones RL \& Dowsett M 2006 Cyclin D1 protein overexpression and CCND1 amplification in breast carcinomas: an immunohistochemical and chromogenic in situ hybridisation analysis. Modern Pathology 19 999-1009. (https://doi.org/10.1038/modpathol.3800621)

Rodriguez-Pinilla SM, Jones RL, Lambros MB, Arriola E, Savage K, James M, Pinder SE \& Reis-Filho JS 2007 MYC amplification in breast cancer: a chromogenic in situ hybridisation study. Journal of Clinical Pathology 60 1017-1023. (https://doi.org/10.1136/ jср.2006.043869)

Sanders ME, Schuyler PA, Dupont WD \& Page DL 2005 The natural history of low-grade ductal carcinoma in situ of the breast in women treated by biopsy only revealed over 30 years of long-term follow-up. Cancer 103 2481-2484. (https://doi.org/10.1002/cncr.21069)

Schymik B, Buerger H, Kramer A, Voss U, van der Groep P, Meinerz W, van Diest PJ \& Korsching E 2012 Is there 'progression through grade' in ductal invasive breast cancer? Breast Cancer Research and Treatment 135 693-703. (https://doi.org/10.1007/s10549-012-2195-1)

Shi X \& Wang X 2015 The role of MTDH/AEG-1 in the progression of cancer. International Journal of Clinical and Experimental Medicine $\mathbf{8}$ $4795-4807$.

Siegel RL, Miller KD \& Jemal A 2015 Cancer statistics, 2015. CA: A Cancer Journal for Clinicians 65 5-29. (https://doi.org/10.3322/ caac. 21254)
Sircoulomb F, Nicolas N, Ferrari A, Finetti P, Bekhouche I, Rousselet E, Lonigro A, Adelaide J, Baudelet E, Esteyries S, et al. 2011 ZNF703 gene amplification at $8 \mathrm{p} 12$ specifies luminal B breast cancer. $E M B O$ Molecular Medicine 3 153-166. (https://doi.org/10.1002/ emmm.201100121)

Slamon DJ, Clark GM, Wong SG, Levin WJ, Ullrich A \& McGuire WL 1987 Human breast cancer: correlation of relapse and survival with amplification of the HER-2/neu oncogene. Science 235 177-182. (https://doi.org/10.1126/science.3798106)

Span PN, Tjan-Heijnen VC, Manders P, Beex LV \& Sweep CG 2003 Cyclin-E is a strong predictor of endocrine therapy failure in human breast cancer. Oncogene 22 4898-4904. (https://doi.org/10.1038/sj. onc.1206818)

Spellman P \& Gray J 2011 A new treasure in the breast cancer gene hunt. Nature Medicine 17 422-423. (https://doi.org/10.1038/ nm0411-422)

Staff S, Isola J, Jumppanen M \& Tanner M 2010 Aurora-A gene is frequently amplified in basal-like breast cancer. Oncology Reports $\mathbf{2 3}$ 307-312.

Tokunaga E, Nakashima Y, Yamashita N, Hisamatsu Y, Okada S, Akiyoshi S, Aishima S, Kitao H, Morita M \& Maehara Y 2014 Overexpression of metadherin/MTDH is associated with an aggressive phenotype and a poor prognosis in invasive breast cancer. Breast Cancer 21 341-349. (https://doi.org/10.1007/s12282012-0398-2)

Turner N, Pearson A, Sharpe R, Lambros M, Geyer F, Lopez-Garcia MA, Natrajan R, Marchio C, Iorns E, Mackay A, et al. 2010 FGFR1 amplification drives endocrine therapy resistance and is a therapeutic target in breast cancer. Cancer Research 70 2085-2094. (https://doi.org/10.1158/0008-5472.CAN-09-3746)

Vermeulen MA, Slaets L, Cardoso F, Giordano SH, Tryfonidis K, van Diest PJ, Dijkstra NH, Schroder CP, van Asperen CJ, Linderholm B, et al. 2017 Pathological characterisation of male breast cancer: results of the EORTC 10085/TBCRC/BIG/NABCG International Male Breast Cancer Program. European Journal of Cancer 82 219-227. (https://doi. org/10.1016/j.ejca.2017.01.034)

Wolff AC, Hammond ME, Hicks DG, Dowsett M, McShane LM, Allison KH, Allred DC, Bartlett JM, Bilous M, Fitzgibbons P, et al. 2013 Recommendations for human epidermal growth factor receptor 2 testing in breast cancer: American Society of Clinical Oncology/ College of American Pathologists clinical practice guideline update. Journal of Clinical Oncology 31 3997-4013. (https://doi.org/10.1200/ JCO.2013.50.9984)

Received in final form 8 November 2017

Accepted 4 December 2017

Accepted Preprint published online 4 December 2017
(2) 2018 Society for Endocrinology Published by Bioscientifica Ltd. Printed in Great Britain 